\title{
Walking to school and traffic exposure in Australian children
}

\author{
John B. Carlin \\ Clinical Epidemiology and Biostatistics Unit, University of Melbourne Department of Paediatrics, and \\ Royal Children's Hospital, Melbourne
}

Mark R. Stevenson

Department of Epidemiology and Biostatistics, Curtin University of Technology, Perth

Ian Roberts

Child Health Monitoring Unit, Institute of Child Health, London

Catherine M. Bennett

Clinical Epidemiology and Biostatistics Unit, University of Melbourne Department of Paediatrics, and Royal Children's Hospital, Melbourne

Andrew Gelman

Department of Statistics, Columbia University, New York

\author{
Terry Nolan \\ Clinical Epidemiology and Biostatistics Unit, University of Melboume Department of Paediatrics, and \\ Royal Children's Hospital, Melboume
}

\begin{abstract}
Daily patterns of pedestrian activity in young children have important health implications, primarily because of the risk of road traffic injury, but also because they may reflect the commencement of exercise habits with long-term consequences. A crosssectional survey in two Australian cities, Melbourne and Perth, aimed to collect, by parent self-administered questionnaire, population-based data on modes of travel, numbers of street crossings (both accompanied and unaccompanied by an adult), and sociodemographic factors for six- and nine-year-old children. Results indicate that 35 per cent (95 per cent confidence interval (CI) 31 to 39 per cent) and 31 per cent (CI 28 to 34 per cent) walk to school in Melbourne and Perth respectively, while over 60 per cent are driven to school by car, with very small proportions riding bicycles or taking public transport. A higher level of walking was associated with lower levels of several indicators of socioeconomic status. Logistic regression analysis showed that the strongest predictor of walking activity was school type (government versus independent), and after adjusting for this, lesser car ownership, non-English-speaking background and lower occupational category were associated with walking to school, while a different set of predictors-age, sex and maternal education - was associated with the unaccompanied crossing of streets. There was little difference in overall walking levels between boys and girls, but boys were significantly more likely to cross streets unaccompanied (adjusted odds ratio 1.41, CI 1.14 to 1.72), providing a partial explanation of documented sex differences in injury rates. (Aust N Z J Public Health 1997; 21: 286-92)
\end{abstract}

$\mathrm{U}$ NDERSTANDING the extent to which children walk and bicycle as part of their daily routine is important for a number of reasons. First, road traffic collisions involving children as pedestrians or cyclists are a leading cause of death in school children and a major cause of long-term disability. In 1991, 31 Australian children aged

Correspondence to Dr John Carlin, Clinical Epidemiology and Biostatistics Unit, Royal Children's Hospital, Parkville, Vic 3052. Fax (03) 93456000 . between 5 and 14 years were killed as pedestrians and 16 as cyclists, and a further 3500 children were seriously injured. ${ }^{1}$

Despite the magnitude of the problem, many basic epidemiologic questions remain unanswered. In particular, why did mortality rates for road traffic collisions involving children as pedestrians in Australia decline almost threefold between 1980 and 1994 (Federal Office of Road Safety, personal communication)? To what extent can this be attributed to improvements in the urban traffic environment, 
or alternatively to a reduction in children's exposure to the risk of pedestrian injury, that is, a reduction in walking activity? Why are pedestrian injury rates for boys significantly higher than those for girls? Why are poor children overrepresented among pedestrian casualties? ${ }^{2,3}$ Why do more pedestrian accidents happen on the journey home from school than on the journey to school? ${ }^{3,4}$ Many of these questions might be answered by a more detailed knowledge of children's patterns of walking and cycling.

A second reason for studying children's walking and cycling behaviour is that physical activity patterns acquired in childhood may have important implications for adult health. In adults, the health advantages of regular physical exercise are well established and include a reduced risk of heart disease, conservation of bone mass and enhanced psychological wellbeing. However, the most important argument for promoting physical activity in childhood is based on the assumption that life-style patterns of physical activity in childhood carry over into adult life. ${ }^{5-8}$ Children who regularly walk and cycle are likely to become adults who regularly walk and cycle. Although the importance of such ordinary everyday activities for children has been emphasised, there is very little information on the daily patterns of ordinary physical activity in school children.

This paper provides answers to some of the questions and provides baseline data against which others may be investigated, by reporting the results of a cross-sectional survey of the walking and cycling activity of young school children in Melbourne and Perth. In order to collect valid and reliable information, the survey used a simple questionnaire for parents, focusing on the major measures pertinent to pedestrian injury risk and travel-related physical activity for a single school day: the child's mode of travel to and from school and number of streets crossed with and without adult accompaniment; while going to and from school as well as before and after school. The emphasis on travel between school and home was motivated by the fact that this is the single major journey all children make each school day, and there is evidence that a large proportion of pedestrian injuries occur on this journey. ${ }^{9}$ The number of street crossings was the principal measure of exposure to risk because street crossing is required for a collision to occur and it has been shown that parents provide valid data on this measure. ${ }^{10}$ We focused on children aged six and nine years, because several studies have indicated that child pedestrian injury rates are highest in this age range. ${ }^{3,11}$ The questionnaire and survey method were standardised across centres participating in INSECT (an international study of the exposure of children to traffic) and international comparisons will be reported separately.

\section{Methods}

Children and parents were selected to participate in the survey by means of a two-stage random clustersampling design. Schools were selected with a probability proportional to the school's total enrolment in the age groups of interest (stratified according to whether they were public, Catholic or independent) from all schools with an enrolment of at least 100 pupils in the Melbourne and Perth metropolitan areas. Outer suburban municipalities where the population density was less than 500 persons per square kilometre were excluded. Within each school it was intended that a complete class of Year 1 (age six) and Year 4 (age nine) students would be selected at random from the available classes, although in a number of schools where classes were organised in mixed grades, combined (Year 1-2, 3-4 etc.) classes were selected. In the Perth sample, entire Year 1 and 4 levels were included in the survey. The number of schools was chosen with the aim of obtaining 1500 children in each of the age groups to be studied (based on a sample-size calculation requiring 80 per cent power to detect a difference between age groups of 0.5 streets crossed per day, adjusting for an assumed intraclass correlation of 0.05 in the outcome measure)

Pedestrian activity was measured with a questionnaire that the child and parent were asked to complete on the evening of distribution by systematically reviewing the child's walking activity for that day. The questionnaire divided the day into four parts (before school, going to school, coming home from school and after school) and asked whether the child walked in each period, and if so, how many streets were crossed, and whether the child was alone or accompanied (the latter including possible use of attended school crossings). Parents were also asked to estimate how much time the child spent as a pedestrian, whether on the road, footpath or nature strip; such a question could not be expected to produce reliable quantitative information and the response was dichotomised for analysis. The questionnaire was pilot-tested in both cities, and minor improvements were incorporated. The schools participating in the study were asked to record which students had returned questionnaires, and after about a week, forms were reissued to nonrespondents. An incentive scheme was used to enhance response rates in the Melbourne study. Final response rates were calculated as the proportion of all students issued a questionnaire who returned the form with usable information on the child's walking.

Analysis used the statistical package, Stata, and followed standard principles for analysing cluster samples. ${ }^{12,13}$ To ensure that intraschool correlations were adequately controlled for, and to compensate for differences in response rates between schools, analyses were based on cluster-specific means. Overall population means (of number of streets crossed, proportion walking to school etc.) were estimated as the means of the cluster means, with standard errors and confidence intervals for population means obtained by applying the usual formula $(\mathrm{SD} / \sqrt{k})$ to the cluster means (where $k$ is the number of clusters and SD the standard deviation of the cluster means). To account for the varying numbers in subcategories (by age, sex and other covariates of interest), mean values for population subcategories were estimated by weighted means of the cluster-specific mean values, weighted in proportion to the sample number 
Table 1: Mode of travel used for the journey to and from school, and mean number of street crossings, by age and sex, for six- and nine-year old children in Melbourne and Perth, 1994

\begin{tabular}{|c|c|c|c|c|c|c|c|c|c|c|c|c|}
\hline \multirow{4}{*}{$\begin{array}{l}\text { Journey and } \\
\text { mode of transport }\end{array}$} & \multicolumn{4}{|c|}{$\begin{array}{l}\text { Melbourne } \\
\text { By age and sex }\end{array}$} & & & \multicolumn{6}{|c|}{$\begin{array}{l}\text { Perth } \\
\text { and sex }\end{array}$} \\
\hline & \multicolumn{2}{|c|}{6 years } & \multicolumn{2}{|c|}{9 years } & \multirow{2}{*}{\multicolumn{2}{|c|}{$\begin{array}{l}\text { Overall } \\
\text { Standard }\end{array}$}} & \multicolumn{2}{|c|}{6 years } & \multicolumn{2}{|c|}{9 years } & \multirow{2}{*}{\multicolumn{2}{|c|}{$\begin{array}{l}\text { Overall } \\
\text { Standard }\end{array}$}} \\
\hline & Boys & Girls & Boys & Girls & & & Boys & Girts & Boys & Girls & & \\
\hline & $\%$ & $\%$ & $\%$ & $\%$ & $\%$ & error & $\%$ & $\%$ & $\%$ & $\%$ & $\%$ & error \\
\hline \multicolumn{13}{|l|}{ Journey to school } \\
\hline Walked & 30 & 25 & 32 & 33 & 30.6 & 1.9 & 26 & 25 & 27 & 30 & 27.0 & 1.5 \\
\hline Walked + car & 5 & 4 & 4 & 5 & 4.4 & 0.4 & 5 & 4 & 3 & 4 & 3.9 & 0.5 \\
\hline Car & 63 & 68 & 56 & 57 & 60.2 & 1.9 & 66 & 69 & 57 & 58 & 62.4 & 1.6 \\
\hline Public transport & 1 & 1 & 2 & 2 & 1.7 & 0.4 & 1 & 1 & 1 & 2 & 1.1 & 0.2 \\
\hline Bicycle & 1 & 1 & 6 & 3 & 3.0 & 0.6 & 3 & 2 & 12 & 6 & 5.8 & 0.8 \\
\hline \multicolumn{13}{|l|}{ Journey from school } \\
\hline Walked & 35 & 29 & 38 & 39 & 35.6 & 1.9 & 27 & 27 & 30 & 34 & 29.4 & 1.5 \\
\hline Walked + car & 5 & 5 & 5 & 4 & 4.9 & 0.5 & 5 & 4 & 3 & 4 & 3.9 & 0.4 \\
\hline Car & 57 & 63 & 49 & 52 & 54.5 & 1.8 & 64 & 66 & 53 & 53 & 59.0 & 1.9 \\
\hline Public transport & 2 & 2 & 2 & 2 & 2.1 & 0.4 & 1 & 2 & 2 & 3 & 1.9 & 0.4 \\
\hline Bicycle & 1 & 1 & 6 & 3 & 3.0 & 0.7 & 3 & 2 & 12 & 6 & 5.7 & 0.7 \\
\hline Mean total street crossings & 3.4 & 2.8 & 3.9 & 3.9 & 3.6 & & 2.2 & 1.9 & 2.5 & 2.7 & 2.3 & \\
\hline
\end{tabular}

Note: (a) Column percentages are shown.

and in inverse proportion to the cluster size. Standard errors for these means were obtained from a corresponding weighted variance estimate. (Details of formulas used are available from the first author.) Logistic regression was used to assess the independent association between sociodemographic variables and indicators of walking and traffic exposure, incorporating probability weights to allow for the survey design and robust standard errors to allow for the clustered structure of the data. ${ }^{14}$ Linear regression on continuous measures, such as the number of street crossings, was not possible because of the extreme skewness of these distributions.

The study was approved by Ethics Committees at the Royal Children's Hospital, Melbourne, and Curtin University of Technology, Perth, and by appropriate government and Catholic education authorities in each state.

\section{Results}

The survey was carried out in 72 and 48 schools in Melbourne and Perth, respectively, between September and November, 1994 (spanning a range of spring weather conditions in both centres). In Melbourne, of the originally selected schools, seven declined participation and these were substituted by geographically neighbouring schools; in Perth, five substitutions were made. Of 3963 questionnaires distributed for the Melbourne survey, a total of 3198 usable responses was obtained, a response rate of 82 per cent. Of 4271 questionnaires distributed in the Perth metropolitan area, a total of 2781 usable responses was obtained, representing a response rate of 65 per cent. Approximately 5 per cent and 3 per cent of parents in Melbourne and Perth, respectively, returned blank forms or indicated unwillingness to participate. The analysis considered children in the two age ranges, 5 to 7 years and 8 to 10 years, corresponding to the two class levels. Mean ages within the two groups were slightly higher in the Melbourne sample: 6.9 years and 9.7 years respectively, compared with 6.3 and 9.3 years in Perth (reflecting different school entry policies).

Table 1 shows the modes of transport used for the journey to and from school. In summary, 35 per cent (95 per cent confidence interval (CI) 31 to 39 per cent) of Melbourne children reported walking to school (including those who also went by car for part of the way), 3 per cent rode bicycles and less than 2 per cent used public transport, while most were driven by car. These proportions varied only slightly by age and sex. Perth children reported slightly lower frequency of walking to school (31 per cent, CI 28 to 34 per cent), but this was balanced by a larger number reporting bicycling. In Melbourne, the proportion walking home from school was 5.5 per cent (CI 4.0 to 7.0 per cent) greater than that walking to school; a smaller difference in the same direction was found for Perth (2.5 per cent, CI 0.9 to 4.1 per cent).

The bottom line of Table 1 shows mean numbers of street crossings by age and sex; as with the measure for walking to school, there is little difference between the sexes and a modest difference with age. The mean number of streets crossed before and on the way to school (and after school) differed between those who walked and those who were driven, with children reporting other modes of transport (including a combination of walking and car) having mean numbers of crossings similar to those who reported walking (Table 2). In Melbourne, about half of all street crossings were reported to be in the company of adults, with a smaller proportion in Perth. This difference between the centres reflects primarily a greater use of attended school crossings in Melbourne ( 38 per cent of all respondents reporting at least one use) than in Perth (20 per cent). 
Table 2: Mean numbers of street crossings by children in Melbourne and Perth, 1994, by mode of travel and city

\begin{tabular}{|c|c|c|c|c|c|c|c|c|}
\hline \multirow{3}{*}{$\begin{array}{l}\text { Time and mode of } \\
\text { travel to school }\end{array}$} & \multicolumn{4}{|c|}{ Melbourne } & \multicolumn{4}{|c|}{ Perth } \\
\hline & \multicolumn{2}{|c|}{$\begin{array}{l}\text { Streets } \\
\text { crossed }\end{array}$} & \multicolumn{2}{|c|}{$\begin{array}{l}\text { Streets crossed } \\
\text { without adult }\end{array}$} & \multicolumn{2}{|c|}{$\begin{array}{l}\text { Streets } \\
\text { crossed }\end{array}$} & \multicolumn{2}{|c|}{$\begin{array}{l}\text { Streets crossed } \\
\text { without adult }\end{array}$} \\
\hline & Mean & $\mathrm{Cl}^{\circ}$ & Mean & C & Mean & $\mathrm{Cl}$ & Mean & $\mathrm{Cl}$ \\
\hline \multicolumn{9}{|c|}{ Before and going to school } \\
\hline Walked & 3.1 & & 1.5 & & 2.4 & & 1.4 & \\
\hline Walked + car & 2.4 & & 1.2 & & 1.4 & & 0.8 & \\
\hline Car & 0.5 & & 0.3 & & 0.2 & & 0.1 & \\
\hline Public transport & 2.8 & & 1.5 & & 1.6 & & 0.8 & \\
\hline Bicycle & 3.3 & & 2.7 & & 2.4 & & 1.8 & \\
\hline All & 1.5 & 1.3 to 1.7 & 0.8 & 0.7 to 0.9 & 1.0 & 0.9 to 1.1 & 0.6 & 0.5 to 0.7 \\
\hline \multicolumn{9}{|c|}{ Coming from and after school } \\
\hline Walked & 3.5 & & 1.7 & & 2.7 & & 1.6 & \\
\hline Walked + car & 3.2 & & 1.7 & & 2.2 & & 1.0 & \\
\hline Car & 0.8 & & 0.5 & & 0.5 & & 0.3 & \\
\hline Public transport & 2.9 & & 2.0 & & 1.3 & & 0.9 & \\
\hline Bicycle & 4.2 & & 3.0 & & 2.6 & & 1.9 & \\
\hline All & 2.1 & 1.8 to 2.3 & 1.1 & 0.9 to 1.2 & 1.3 & 1.2 to 1.4 & 0.8 & 0.7 to 0.9 \\
\hline Whole day & 3.6 & 3.2 to 4.0 & 1.9 & 1.6 to 2.1 & 2.3 & 2.1 to 2.5 & 1.4 & 1.2 to 1.5 \\
\hline
\end{tabular}

Note: $($ a) $\mathrm{Cl}=95 \%$ confidence interval.

In Table 3 we present summaries of the crude relationships observed in the Melbourne data between sociodemographic factors and major indicators of pedestrian activity. All of the comparisons using indicators of socioeconomic status show clear trends toward less walking with higher socioeconomic status, although these trends are stronger for the proportion walking to school and the numbers of street crossings than for the proportion spending no more than five minutes walking. Overall, 44 per cent (CI 40.4 to 46.8 per cent) of Melbourne children were reported to spend less than five minutes of the day as pedestrians.

Table 4 presents results of logistic regression analyses of the walking-to-school outcome and the crossed-more-than-one-street-unaccompanied-by-anadult outcome. All the independent variables shown in Table 3 were included in the models, except for home ownership, which did not approach statistical significance in either analysis. There was no significant interaction between age and sex for either outcome, and after adjusting for the other factors in the multiple regression, there were significant age and sex effects only for the street-crossing outcome. Lower maternal education level was also associated with increased likelihood of unaccompanied crossings. In contrast, after adjustment for school type, lack of car ownership, non-English-speaking background and lower occupational status were predictive of walking to school.

\section{Discussion}

The survey indicates that, on school days, young children in Australian cities spend remarkably little time as pedestrians, and even less time walking unaccompanied. In 60 per cent of cases, children are driven to school by car. Ironically, the fact that cars are used so predominantly for transporting children may lead to increased risk of pedestrian injury for those children whose parents are unable or less willing to drive their children. Another finding of interest is that the number of children using bicycles to travel to school is very low. This may indicate that the prevailing emphasis in many school-based traffic safety programs on bicycle safety is misplaced. On the other hand, bicycle use clearly increases with age and may be considerably more common in older children than those studied here; furthermore, other research indicates that young children still use bicycles extensively for play if not for transportation. ${ }^{16}$ In both Melbourne and Perth, few children use public transport to travel to and from school. This finding is not surprising, given that both Melbourne and Perth have low population densities and are highly dependent on the private car for transportation. For example, Perth has the highest ratio of road-metres to population in the world and has more parking facilities (per capita) than any other city in the world. ${ }^{17}$

The results reported are based on self-administered questionnaires, and there may be concerns about the validity of this form of reporting. However, recently conducted research found that the child's exposure to the road environment, as reported in a self-administered questionnaire, did not differ significantly from the researcher's observation of the child. ${ }^{10}$ Slight underreporting of exposure was found in an earlier British study. ${ }^{18}$ The questionnaire used for this study was extensively pretested. Response rates in Melbourne were high for a study of this kind, but the lower rates in Perth imply that comparisons between the two cities need to be made with caution. In spite of differing response rates, the results in the two cities were similar for modes of transport, with the main difference being a higher rate of bicycle use in Perth. 
Table 3: Proportions of children walking to and from school, proportions spending 5 minutes or less as pedestrians, and mean numbers of streets crossed, both total and accompanied by an adult, by demographic and socioeconomic variables, for Melbourne children, 1994

\begin{tabular}{|c|c|c|c|c|c|c|c|c|}
\hline \multirow[b]{2}{*}{ Covariate } & \multicolumn{2}{|c|}{$\begin{array}{l}\text { Walked } \\
\text { to school }\end{array}$} & \multicolumn{2}{|c|}{$\begin{array}{l}\text { Spent } \leq 5 \text { minutes } \\
\text { as pedestrian }\end{array}$} & \multicolumn{2}{|c|}{$\begin{array}{c}\text { Number of streets } \\
\text { crossed }\end{array}$} & \multicolumn{2}{|c|}{$\begin{array}{l}\text { Number of } \\
\text { streets crossed } \\
\text { unaccompanied }\end{array}$} \\
\hline & $\%$ & $2 \times \mathrm{SE}^{\circ}$ & $\%$ & $2 \times S E$ & Mean & $2 \times S E$ & Mean & $2 \times S E$ \\
\hline \multicolumn{9}{|l|}{ Age (years) } \\
\hline $5-7$ & 32.1 & 4.2 & 47.5 & 3.6 & 3.1 & 0.4 & 1.3 & 0.2 \\
\hline $8-10$ & 37.0 & 4.4 & 40.5 & 3.6 & 3.9 & 0.5 & 2.3 & 0.3 \\
\hline \multicolumn{9}{|l|}{ Sex } \\
\hline Boy & 35.4 & 4.3 & 42.7 & 3.3 & 3.7 & 0.4 & 2.0 & 0.2 \\
\hline Girl & 34.3 & 4.3 & 44.4 & 4.1 & 3.4 & 0.5 & 1.7 & 0.3 \\
\hline \multicolumn{9}{|l|}{ School type } \\
\hline Government & 40.0 & 4.3 & 40.3 & 3.8 & 3.7 & 0.4 & 2.0 & 0.3 \\
\hline Catholic & 27.7 & 6.1 & 47.6 & 5.8 & 3.5 & 1.0 & 1.7 & 0.5 \\
\hline Independent & 12.1 & 6.8 & 60.5 & 9.6 & 1.8 & 0.7 & 0.9 & 0.3 \\
\hline \multicolumn{9}{|c|}{ Number of cars in family } \\
\hline 0 & 80.6 & 10.4 & 11.2 & 7.8 & 8.3 & 1.9 & 3.3 & 1.5 \\
\hline 1 & 41.9 & 4.2 & 38.9 & 3.7 & 4.3 & 0.6 & 2.3 & 0.3 \\
\hline$\geq 2$ & 26.8 & 3.6 & 48.8 & 3.7 & 2.8 & 0.3 & 1.5 & 0.2 \\
\hline \multicolumn{9}{|l|}{ Home owned } \\
\hline Yes & 32.7 & 3.7 & 45.0 & 3.3 & 3.2 & 0.3 & 1.7 & 0.2 \\
\hline No & 42.1 & 5.4 & 38.3 & 5.1 & 4.6 & 0.7 & 2.3 & 0.4 \\
\hline \multicolumn{9}{|c|}{ Mother's education } \\
\hline Primary & 38.8 & 4.7 & 41.7 & 4.1 & 3.9 & 0.5 & 2.2 & 0.4 \\
\hline Secondary & 35.6 & 5.2 & 44.7 & 4.4 & 3.4 & 0.5 & 1.5 & 0.2 \\
\hline Tertiary & 29.7 & 3.8 & 44.9 & 4.2 & 3.3 & 0.4 & 1.7 & 0.3 \\
\hline \multicolumn{9}{|c|}{ Language spoken at home } \\
\hline English & 31.6 & 3.9 & 45.4 & 3.5 & 3.2 & 0.3 & 1.7 & 0.2 \\
\hline Other & 44.5 & 5.6 & 38.1 & 5.2 & 4.6 & 0.9 & 2.3 & 0.4 \\
\hline \multicolumn{9}{|c|}{ Occupational status ${ }^{b}$} \\
\hline I st tertile & 28.9 & 4.7 & 44.2 & 4.8 & 3.2 & 0.5 & 1.6 & 0.3 \\
\hline 2nd tertile & 31.1 & 4.3 & 47.1 & 4.4 & 3.0 & 0.3 & 1.5 & 0.2 \\
\hline 3rd tertile & 41.6 & 4.9 & 40.6 & 4.5 & 4.1 & 0.5 & 2.1 & 0.4 \\
\hline
\end{tabular}

Notes:

(a) $\mathrm{SE}=$ standard error; $95 \%$ confidence interval may be obtained as estimate (\% or mean) $\pm 2 \times \mathrm{SE}$.

(b) Assessed with the Daniel scale of occupational prestige; ${ }^{15}$ in these data, the first tertile (highest-prestige occupations) constituted the Daniel range $1.0-3.9$, the second tertile 4.0-4.8, and the third, 4.9-7.0.

A major finding to emerge from this survey is that differences in our measures of exposure do not fully explain sex differences in injury rates. National rates of hospitalisation due to pedestrian injury among boys are 2.1 and 1.7 times those for girls, in the age groups 5 to 7 and 8 to 10 , respectively (Table 5). Many other studies have reported similar risk ratios. ${ }^{3,11,19}$ We have found evidence of a relatively small difference in exposure to traffic, implying that aetiologic factors other than simple exposure, as measured here, are important in determining injury risk. Our results do, however, show larger sex differences when exposure is measured in streets crossed unaccompanied rather than total streets crossed or simply walking to school (Tables 3 and 4). This finding is consistent with other evidence that adult accompaniment may be an important factor in pedestrian injury risk. ${ }^{9}$

This survey showed that a larger proportion of children walk home from school than walk to school, and this no doubt explains part of the peak in child pedestrian injury rates in the mid-afternoon to late afternoon. ${ }^{3}$ Given the cross-sectional and selfadministered nature of our survey, it was not possible to collect more detailed data on injury risk factors such as traffic density and other road characteristics.

The literature on predictors of pedestrian injury risk is relatively weak, but several studies have shown increased risk among the socially more deprived..$^{2,3}$ In our multiple regression analyses of socioeconomic factors as predictors of pedestrian activity, the strongest predictor was school type, and after adjustment for this, lesser car ownership, non-Englishspeaking background and lower occupational category were associated with walking to school. This pattern of association can be interpreted as reflecting economic necessities within less-well-off families as well, perhaps, as cultural differences. It was interesting, however, that a different set of predictors- 
Table 4: Summaries of logistic regression models fitted to data from Melbourne children, $1994^{\circ}$

\begin{tabular}{|c|c|c|c|c|}
\hline \multirow[b]{2}{*}{ Covariate } & \multicolumn{2}{|c|}{$\begin{array}{l}\text { Walked to } \\
\text { school }\end{array}$} & \multicolumn{2}{|c|}{$\begin{array}{l}\text { Crossed > I street } \\
\text { without adult } \\
\text { accompaniment }\end{array}$} \\
\hline & $O R^{b}$ & $\mathrm{Cl}^{\mathrm{c}}$ & OR & $\mathrm{Cl}$ \\
\hline \multicolumn{5}{|l|}{ Age (years) } \\
\hline $5-7$ & 1.00 & - & 1.00 & - \\
\hline $8-10$ & 1.04 & 0.86 to 1.27 & 1.71 & 1.36 to 2.14 \\
\hline \multicolumn{5}{|l|}{ Sex } \\
\hline Boys & 1.00 & - & 1.00 & - \\
\hline Girls & 0.88 & 0.73 to 1.08 & 0.71 & 0.58 to 0.88 \\
\hline \multicolumn{5}{|l|}{ School type } \\
\hline Government & 1.00 & - & 1.00 & - \\
\hline Catholic & 0.49 & 0.36 to 0.67 & 0.78 & 0.53 to 1.14 \\
\hline Independent & 0.29 & 0.13 to 0.64 & 0.43 & 0.36 to 0.52 \\
\hline \multicolumn{5}{|c|}{ Number of cars in family } \\
\hline 0 & 3.1 & 1.1 to 8.5 & 0.77 & 0.32 to 1.87 \\
\hline 1 & 1.00 & - & 1.00 & - \\
\hline$\geq 2$ & 0.46 & 0.37 to 0.57 & 0.79 & 0.63 to 0.99 \\
\hline \multicolumn{5}{|c|}{ Mother's education } \\
\hline Primary & 0.96 & 0.73 to 1.27 & 1.32 & 1.01 to 1.72 \\
\hline Secondary & 1.07 & 0.85 to 1.36 & 1.03 & 0.79 to 1.35 \\
\hline Tertiary & 1.00 & - & 1.00 & - \\
\hline \multicolumn{5}{|c|}{ Language spoken at home } \\
\hline English & 1.00 & - & 1.00 & - \\
\hline Other & 1.45 & 1.09 to 1.92 & 1.02 & 0.84 to 1.24 \\
\hline \multicolumn{5}{|c|}{ Occupational status ${ }^{d}$} \\
\hline 1 st tertile & 1.00 & - & 1.00 & 一 \\
\hline 2nd tertile & 1.10 & 0.85 to 1.43 & 0.95 & 0.72 to 1.25 \\
\hline 3rd tertile & 1.37 & 1.06 to 1.76 & 0.97 & 0.78 to 1.22 \\
\hline
\end{tabular}

Notes:

(a) Estimated with probability weights inversely proportional to each subject's probability of selection and school-level response rate, and using the Huber-White method to provide robust standard error estimates, allowing for intra-school correlations. ${ }^{14}$

(b) $O R=$ odds ratio: baseline categories for each covariate are indicated by $\mathrm{OR}=1.00$

(c) $\mathrm{Cl}=95 \%$ confidence interval.

(d) Assessed with the Daniel scale of occupational prestige; ; $^{15}$ in these data, the first tertile (highest-prestige occupations) constituted the Daniel range 1.0-3.9, the second tertile 4.0-4.8, and the third, 4.9-7.0.

age, sex and maternal education-appeared to be associated with the unaccompanied crossing of streets, after adjustment for school type. Assuming that unaccompanied crossing is a better proxy for exposure to risk of pedestrian injury, our results suggest that socioeconomic differences in risk of injury may be due more to educational and sex factors than strictly economic ones. School type is also a strong indicator of socioeconomic status, but only a small minority of students in the survey (and in the population) attended independent schools. Finally, the strong age difference in unaccompanied street crossing (Tables 3,4), relative to the lack of difference in injury rates (Table 5), reflects the importance of developmental factors in injury risk.

As well as providing data relevant to discussion of child pedestrian injury rates, this survey gives a cross-
Table 5: Incidence rates (per 100000 ) of hospitalisation for pedestrian injury, by age group and sex, for Australia, 1991-92。

\begin{tabular}{|c|c|c|c|c|}
\hline Age group (years) & Boys & Girls & $\begin{array}{l}\text { Relative rate } \\
\text { boys:girls }\end{array}$ & $\mathrm{Cl}^{\mathrm{b}}$ \\
\hline $5-7$ & 47.2 & 22.3 & 2.1 & 1.6 to 2.8 \\
\hline $8-10$ & 41.7 & 24.8 & 1.7 & 1.3 to 2.2 \\
\hline $\begin{array}{l}\text { Relative rate } \\
(5-7: 8-10) \\
\mathrm{Cl}\end{array}$ & $\begin{array}{c}1.1 \\
.91 \text { to } 1.4\end{array}$ & $\begin{array}{c}0.9 \\
0.66 \text { to } 1.2\end{array}$ & & \\
\hline
\end{tabular}

Notes:

(a) Data courtesy of National Injury Surveillance Unit, Adelaide (personal communication).

(b) $\mathrm{Cl}=95 \%$ confidence interval.

sectional insight into one aspect of general physical activity among young children. The data support an overwhelming impression of children relying on family cars for most transportation purposes. Only about half of the children surveyed were reported to spend more than five minutes of the day as pedestrians. It seems likely that such a pattern of being driven everywhere may contribute to lower general levels of physical activity. Several studies have highlighted the potential importance of social factors and activity patterns in childhood as predictors of long-term fitness and health. ${ }^{6-8}$ There is evidence of a direct association between levels of general physical activity in adulthood and all-cause mortality. ${ }^{20}$ The transportation patterns described here also lend support to broader concerns that the psychological development of children may be impaired by curtailment of their sense of independence and personal mobility. ${ }^{21,22}$ Finally, however, it must be remembered that this survey did not attempt to estimate the extent of children's pedestrian activity on non-school days, when exposure to traffic and patterns of general activity may be different.

\section{Acknowledgments}

The study was funded by the Federal Office of Road Safety, Department of Transport, Canberra (for the Melbourne component) and the Western Australian Health Promotion Foundation, Healthways (Perth component). We wish to thank the Directorates of School Education and Catholic Education Offices in both Victoria and Western Australia for allowing access to schools, and we thank especially all the principals, teachers and other school staff who provided assistance. We also thank the referees for helpful comments that led to substantial improvements in the paper.

\section{References}

1. O'Connor PI, Trembath RF. Road injury in Australia, 1991. Adelaide: National Injury Surveillance Unit, 1995.

2. Kendrick D. Prevention of pedestrian accidents. Arch Dis Child 1993; 68: 669-72.

3. Rivara FP, Barber M. Demographic analysis of childhood pedestrian injuries. Pediatrics 1985; 76: 375-81. 
4. Tight MR. A study of the accident involvement and exposure to risk of child pedestrians on journeys to and from school in urban areas. In: Rothengatter $\mathrm{T}, \mathrm{De}$ Bruin $\mathrm{R}$, editors. Road user behaviour: theory and research. Assen-Maastricht: Van Gorcum, 1988: 185-91.

5. Young and unfit [editorial]. Lancet 1992; 340: 19-20.

6. Rowland TW, Freedson PS. Physical activity, fitness and health in children: a closer look. Pediatrics 1994; 93: 669-72.

7. Riddoch C, Savage JM, Murphy N, Cran GW, Boreham C Long term health implications of fitness and physical activity patterns. Arch Dis Child 1991; 66: 1426-33.

8. Kuh DJL, Cooper C. Physical activity at 36 years: patterns and childhood predictors in a longitudinal study. I Epidemiol Community Health 1992; 46: 114-19.

9. Roberts I. Adult accompaniment and the risk of pedestrian injury on the school-home journey. Injury Prev 1995; 1 : $242-4$.

10. Stevenson $\mathbf{M}$. The validity of children's self-reported exposure to traffic. Accid Anal Prev 1996; 28: 599-605.

11. Guyer B, Talbot AM, Pless IB. Pedestrian injuries to children and youth. Pediatr Clin North Am 1985; 32: 163-74.

12. Stata statistical software. Release 4.0. College Station, TX: Stata Corporation, 1995

13. Cochran WG. Sampling techniques. 3rd edn. New York: Wiley, 1977: chapter 11

14. Rogers W. sg 17: regression standard errors in clustered samples. In: Becketti S, editor. Stata technical bulletin reprints. Vol. 3. College Station, TX: Stata Corporation, 1994: 88-94.
15. Daniel A. Power, privilege and prestige: occupations in Australia. Melbourne: Longman Cheshire, 1983.

16. Carlin JB, Taylor P, Nolan TM. A case-control study of child bicycle injuries: relationship of risk to exposure. Accid Anal Prev 1995; 27: 839-44.

17. Newman P, Kenworthy J. Cities and automobile dependence: an international sourcebook. Sydney: Gower Technical, 1991.

18. Routledge DA, Repetto-Wright R, Howarth CI. A comparison of interviews and observation to obtain measures of children's exposure to risk as pedestrians. Ergonomics 1974; 17 : 623-38.

19. Barancik JI, Chatterjee BF, Greene-Cradden YC, Michenzi $\mathrm{EM}$, et al. Motor vehicle trauma in northeastern Ohio. I: Incidence and outcome by age, sex, and road-use category. Am J Epidemiol 1986; 123: 846-61.

20. Paffenberger RS, Hyde R'T, Wing AL, Hsieh C-C. Physical activity, all-cause mortality, and longevity of college alumni. NEngl J Med 1986; 314: 605-13.

21. Hillman M, Adams J, Whitelegg J. One false move: a study of children's independent mobility. London: Policy Studies Institute, 1991.

22. Tranter PJ. Children's mobility in Canberra: confinement or independence. Monograph series no. 7. Canberra: Department of Geography, University College, Australian Defence Force Academy, 1993. 